\title{
The Effect of Gender on Cognitive Structuring: Who are More Biased, Men or Women?
}

\author{
Yoram Bar-Tal ${ }^{1}$, Maria Jarymowicz ${ }^{2}$ \\ ${ }^{1}$ Department of Nursing, School of Health Professions, Sackler Faculty of Medicine, Tel Aviv University, Tel Aviv, Israel; ${ }^{2}$ Faculty \\ of Psychology, Warsaw University, Warsaw, Poland. \\ E-mail: yoramb@post.tau.ac.il
}

Received May $6^{\text {th }}, 2010$; revised May 25 ${ }^{\text {th }}, 2010$; accepted June $3^{\text {rd }}, 2010$.

\begin{abstract}
The effect of gender on the use of cognitive structuring (CS) is examined in three studies $(n=356)$. Study 1 showed that Israeli men use less diagnostic information (display more confirmation bias) than Israeli women. Study 2 demonstrated that Polish adolescent male but not female were influenced by implicit cues in a judgment task a Study 3 showed that the correlation between trait anxiety and the state anxiety measures, in first degree relatives of patients in a cardiac intensive care unit in Israel, was significantly higher for Israeli men than for women. According to the findings of the three studies, women use cognitive structuring to a lesser degree than men do.
\end{abstract}

Keywords: Gender, Cognitive Structuring, Confirmation Bias, TSAI, Self Reference Effect

\section{Introduction}

Ample evidence demonstrates the existence stereotypes about gender differences: men are more rational than women, while women are more emotional, intuitive and biased [1]. Meyers-Levy [2] has hypothesized that indeed men and women use different information processing strategies. However, the direction of the difference she hypothesizes is quite contrary to the stereotypes. In her Selectivity Hypothesis Meyers-Levy [2] theorizes that men are considered to be "selective processors" who often do not engage in comprehensive processing of all available information before rendering judgment. Instead, they seem to rely on various heuristics in place of detailed information processing. These heuristics involve a cue or cues that are highly available and salient and convergently imply a particular inference. Women, on the other hand, are considered to be "comprehensive processors" who attempt to assimilate all available information before rendering judgment.

Despite the importance of the issue and the general interest in gender differences, very limited effort has been made to examine the validity of the Meyers-Levy [2] hypothesis. Among the few studies that have examined this question is Martin's [3] study, which showed that men and women are affected differently by promotional messages. Women were found to process promotional information more comprehensively than men, while men focused on more peripheral information. This implies that men use schema based heuristic strategies to process information. Hayes, Allinson and Armstrong [4] found, similarly, that women use more analytical (less intuitive) information processing than men. Since the relevant studies are so few and mostly performed in English speaking countries, however, one can criticize their conclusions as representing specific content areas, cultures, or methodologies rather than the general phenomenon they purport to validate. For example, it is possible that shopping behavior are more related to the female role and that women are therefore more motivated to invest the additional effort necessary for piecemeal processing. A more effective examination of the validity of the Meyers-Levy [2] hypothesis would center on examining the general processing strategies characteristic of each gender and would deploy multiple methods and content areas and in different countries.

The present paper is designed to examine the effect of gender on the use of cognitive structuring (CS) versus piecemeal processing. Piecemeal processing involves vigilant behavior, consisting of a bottom-up, systematic and effortful search for relevant information, and the evaluation and unbiased assimilation of that information. CS has been defined as "the creation and use of abstract mental representations (e.g., schemata, prototypes, scripts, attitudes, and stereotypes) - representations that are simplified generalizations of previous experience" [5]. (The conceptualization of the contrast between CS and piecemeal is also described in terms of heuristic thinking and 
systematic processing [6]).

CS allows individuals to attain certainty most efficiently because it is relatively automatic, effort-free and faster than piecemeal processing [7,8]. It helps reach certainty by filtering out inconsistent and/or irrelevant information [9] and may make use of previously stored information if needed to attain certainty as to the validity of the inference $[9,10]$. CS is often identified with holistic and top-down processing. These characteristics make CS very effective. In this vein, Macrae and Bodenhausen [11] suggested that using CS helps the perceiver to make the world a meaningful, orderly, and predictable place.

In addition, however, to the very functional characteristics of CS it also characterized with the use of crudely differentiated categories, stereotypical thinking, and heuristic, and biased cognition $[12,13]$. The association between CS and the use of biases is explained by the lower utilization of the relevant information as well as the relying on previously stored information that might be in form of stereotypes or other schema [14].

This paper presents three studies designed to examine the effect of gender on the use of CS in information processing, utilizing different methodologies and participants from different age groups, cultures, and level of education. The first study examines the preference for utilizing available diagnostic information (rather than schemaconsistent information). Specifically, participants were requested to judge the informative value of behavioral cues that were either schema consistent or inconsistent. It is assumed that the extent of relative importance attributed to schema consistent and inconsistent information represents CS. The second study examines the extent participants used the self-schema to interpret neutral stimulus, using implicit (rather than explicit measurement). It is assumed that CS processing is manifested in greater utilization of self-schema information in the judgment task. Finally, the third study explores the effect of gender on the relationship between state and trait anxiety. It is assumed that trait-state relationship represents CS if the trait (self-schema) is used to interpret the situation (the state characteristics). The authors hypothesize that in all operationalizations of CS in this paper, men will exhibit a higher level of CS use than women will.

\section{Study 1}

Study 1 was designed to demonstrate that gender affects the use of schema-inconsistent but diagnostic information. The tendency to use or to avoid this type of information has been studied extensively within the phenomenon of confirmation bias. Confirmation bias is defined as the tendency, when examining the validity of a hypothesis, to prefer to corroborative rather than refuting evidence [15]. Several types of confirmation bias have been identified $[15,16]$. Study 1 focuses on only one, the tendency to avoid examining rival hypotheses. The phenomenon of confirmation strategies has been validated [17-20] but other researchers claim that people use a diagnostic rather than a confirmation strategy in hypothesis testing [16,21-24]. Thus, people are capable of using both confirmatory and diagnostic strategies. We suggest that confirmation bias is the result of a CS process that allows people to achieve certainty with a low expenditure of effort by mainly attending to schema-consistent information and ignoring schema-inconsistent or irrelevant information. This theoretical reasoning is similar to that of Kruglanski and Mayseless [25], that is, people who are motivated to use CS tend to search for prototypical rather than diagnostic (schema-inconsistent) information, whereas people who are motivated to use piecemeal processing do the opposite. Our hypothesis, therefore, is that women will show greater preference for schema inconsistent and diagnostic information than men show and so show less confirmation bias.

\subsection{Method}

\subsubsection{Participants}

One hundred women and 136 men Israelis, all with university education participated in the study. Their average age was 39.05 years $(\mathrm{SD}=10.03)$. There was no significant difference between genders in terms of age or education.

\subsubsection{Measurements}

Stimuli: Participants were presented, in random order, with written impressions of two persons they had supposedly just met, one honest, the other friendly. These impressions functioned to create a hypothesis about the target person. Each impression was followed by 15 information segments regarding the target person's behaviors. Participants were requested to imagine that they wanted to check whether their first impression was correct. They could do so by examining the list of behaviors and rating each behavior on a six-point scale (from "Information not important at all" (1) to "Very important information" (6)). The list of behaviors consisted of five prototypical items, i.e., items consistent with the impression, five diagnostic items, i.e., items inconsistent with the impression, and five items irrelevant to the impression (distraction items). In the case of the honest person, an example of a prototypical item might be "Delivered to the police station money he/she found in the street". An inconsistent item was "Has an extramarital love affair while repeatedly telling the spouse that he/she is faithful". An irrelevant item was "Lives in Ramat Hasharon" (a town in Israel). In the case of the friendly target person, an example of a prototypical item might be "Volunteered to care for lonely older people", an inconsistent item was "Refused to talk with other participants on an organized trip", and an irrelevant item was "Reads Ma'ariv" (an Israeli daily newspaper). Five judges had to validate the 
items by sorting them into one of three categories: relevant and consistent with the hypothesis, relevant but directly refuting the hypothesis, and completely irrelevant to the hypothesis. For each item to be included, at least $80 \%$ of the judges had to agree.

Based on the study participants' responses to the items regarding the two target persons, two indices were created by averaging the 10 items in each category. The Cronbach's alpha reliability of the hypothesis-consistent index was $\alpha=0.88$, and of the hypothesis-inconsistent index $\alpha$ $=0.86$.

\subsubsection{Procedure}

Participants were approached at their place of employment by the researcher and asked to volunteer for a decision-making study. The response rate was $84 \%$. Upon completion, participants were debriefed.

\subsection{Results and Discussion}

To examine the hypothesis that men use more CS and therefore, will demonstrate more confirmation bias, a confirmation bias index was created by subtracting the inconsistent information index from the consistent information index. Lower values on this new index implied a lower showing of confirmation bias, i.e., the informative value of inconsistent items is considered to be closer to that of consistent items. A t-test showed that men's confirmation bias $(\mathrm{M}=1.43 \mathrm{SD}=1.09)$ was significantly higher than women's $(\mathrm{M}=1.09 \mathrm{SD}=0.96)(\mathrm{t}(234)=$ $2.52, \mathrm{p}<0.01)$, which supported the study hypothesis that women tended to use cognitive structuring less than men.

The conclusion of this study contradicts other studies that reported lack of effect of gender on confirmation bias. Marsh and Hanlon [26], for example, reported that man do not differ in the extent of searching information consistent with a given hypothesis. In contrast, Chung and Monroe [27] found that female participants rated inconsistent information as more important than male participants did. It is possible that the explanation for the contradicting results is in the method of operationalization of the concept of confirmation bias. In the present study, by virtue of using the confirmation bias index that reflects both schema consistent as well as schema inconsistent information preference, we can conclude that the results of Study 1 demonstrate that women use less confirmation bias (and therefore, less CS) than men do.

\section{Study 2}

Study 1 demonstrated that women are more sensitive to schema-inconsistent information than men and so use CS less. However, the authors noted that Study 1's outcome variables consisted of an explicit measure that could have influenced the results. For example, Skov and Sherman [23] suggest that asking participants about the utility of various kinds of available information (exactly what was done in Study 1) focuses the participants' attention on the diagnosticity of that information. Perhaps the women complied more with the instructions than the men. To cover this possibility, a more implicit and non-obtrusive method was needed. In Study 2, therefore, we tested our hypothesis examining the Self Reference Effect (SRE) [28] on the implicit level of information processing. Studies on the SRE show specific, universal rules of information processing about the self $[29,30]$. One of them leads to positivity bias [31] which may displayed in overestimation of positive traits, one possess, and under- estimation of negative ones.

In the present study, to measure SRE effect, we used the implicit priming paradigm of Murphy and Zajonc [32]. The original method consist neutral, novel, unfamiliar targets (like Chinese ideograms or hexagrams) subliminally primed with the affective stimulus - participants have to interpret meaning of targets and they are not aware of the influence of implicit cues on their judgments. Błaszczak $[33,34]$ made a modification using affective primes, and requesting participants to guess if a given Chinese represents a trait characteristic for the self.

Because the self is more accessible in memory than other cognitive structures it is an important source for the interpretation of ambiguous cues. For example, Candinu and Rothbart [35] have demonstrated that participants used self-knowledge to give meaning to their novel and unfamiliar situation (for similar results, see Otten \& Bar-Tal [36]). Study 2 referred to the fact that valence is represented as an attribute of the self-schema. The study was designed, therefore, to examine the extent to which gender affects the tendency of respondents to associate the self with implicit signals of valence. We hypothesized an interaction effect in which since men use CS more than women do, the prime valence would be connected with the self more among them (stronger effect of the valance of the implicit traits) than among women.

\subsection{Method}

\subsubsection{General Design}

The study had two phases. The first aimed to provoke activation of the self-schema. Participants were requested to describe themselves using 20 positive and negative traits on a seven-point scale. In the second, a Blaszczak [33] modification of the implicit priming paradigm [32] was introduced. We presented participants with neutral stimuli-hexagrams - as symbols of human different traits. Each hexagram was primed on a subliminal level with positive and negative words - the same 20 traits used earlier. Participants were requested to make judgments as to what extent each target stimuli represented trait relevant to the self. Thus, the independent variables in the study were the valance of the priming and the 
gender of the participant.

\subsubsection{Participants}

The participants were Polish high-school junior year students, 16 boys and 14 girls who volunteered for the study.

\subsubsection{Instruments}

Self-descriptive adjectives: The self-descriptive ques- tionnaire comprised 20 adjectives, 10 positive (e.g., "loyal", "creative", "efficient") and 10 negative ("lazy", "naïve", "quarrelsome"), selected from a representative list of personal descriptions, constructed and validated in Polish by Lewicka [37]. We selected adjectives to achieve a small variance of valence within each category (negative and positive) and a number of letters between six and eight. For each adjective, participants had to rate themselves from "Much less than others" (1) to "Much more than others" (7).

Priming procedure: Using a PC with Pentium 750 MHZ processor with a 17 " monitor and the SuperLab Pro v.1.04 program, each adjective was presented to participants subliminally with $75 \mathrm{~ms}$ exposure time.

Target stimuli: After each adjective had been presented subliminally, participants were presented with a neutral stimulus (Chinese hexagrams) for $1000 \mathrm{~ms}$. Before starting, participants were told "Hexagrams are symbols from the Chinese philosophy of nature. You will be presented with hexagrams representing different human traits. Your task is to assess to what extent the hexagram presented on the screen symbolizes a trait that you possess". To mask primes, hexagrams appeared in the same location on the screen as the primed adjective. Primes and hexagrams were presented in random and counter-balanced order. Participants responded by pressing a number key on a keyboard, ranging from 1 ("definitely NOT ME") to 5 ("definitely ME"). Two variables were calculated based on participants' responses: the average of the relatedness to the self of 10 estimates of the hexagrams primed with positive traits $(\alpha=0.87)$ and 10 with negative ones $(\alpha=0.85)$.

\subsubsection{Procedure}

After obtaining the approval of the high school authorities to conduct the study, it was presented to the junior year students as research into impression formation and human intuition. Students were assured that participation is strictly anonymous. Volunteers were tested individually. All students that were requested agreed to participant in the study.

The first stage was for participants to complete a selfdescriptive questionnaire. Then they were presented with two pictures of groups of young people of both genders. In the first picture, participants had to guess, from their posture of the people, who were in romantic relationships. In the second picture, participants had to guess who earned the most money. The point of these two tasks was to convince participants that the study was designed to examine human intuition. After the priming procedure, the target stimuli appeared on the screen. The following sequence was followed in each trial: a fixation dot appeared on the screen accompanied by a sound; the positive or negative priming trait appeared subliminally, followed by hexagrams; participants responded to the question that appeared on the screen asking how characteristic the trait, symbolized by a given hexagram, was of them. The initial eight trials consisted of hexagrams without priming and were used for training. The actual data stage consisted of 20 trials. Upon completion, participants were debriefed.

\subsection{Results and Discussion}

To test the study hypothesis of which women will be less influenced by the primed valance, a $2 \times 2$ within-between ANOVA was performed, with gender as a 'between' factor and the valence of the priming word as a 'within' factor. A significant main effect of the valence of the priming words was found: hexagrams in positively primed words were rated as more relevant to self $(\mathrm{M}=$ $3.04 \mathrm{SD}=0.49)$ than those in negatively primed words $(\mathrm{M}=2.82 \mathrm{SD}=0.58)(\mathrm{F}(1,28)=4.01, \mathrm{p}=0.05)$. In addition, the analysis yielded a significant interaction $(\mathrm{F}(1,28)$ $=4.02, \mathrm{p}=0.05)$. Table 1 presents the cell means and shows that priming had a greater effect on men than on women. The a posteriori Tukey/b test showed a significant priming effect on men but not on women. These results can be interpreted as supporting the study hypothesis. However, the lower impact of the priming on women may also be attributable to the women's lower self-esteem, that is, to a stronger association between self and negative valence in women than in men. To test this possibility another $2 \times 2$ within-between ANOVA was performed on the positive and negative traits participants ranked themselves at the beginning of the study. Results showed only a main valence effect for the adjectives: positive adjectives $(\mathrm{M}=4.45, \mathrm{SD}=0.81)$ were judged as more relevant to the self than negative traits $(\mathrm{M}=3.63$, $\mathrm{SD}=0.59)(\mathrm{F}(1,28)=14.82, \mathrm{p}<0.01)$. Since neither gender nor gender-by-valence interaction achieved significance, it indicates that the men in this experiment did not differ a priori from the women in their self-esteem. Therefore, the second explanation, women's lower selfesteem, can be discounted.

Table 1. Implicit self reference effect as a function of gender $^{1}$

\begin{tabular}{ccc}
\hline & Positive & Negative \\
\hline $\mathrm{M}$ & $3.01( \pm 0.55)$ & $2.58( \pm 0.58)$ \\
$\mathrm{F}$ & $3.07( \pm 0.44)$ & $3.07( \pm 0.48)$
\end{tabular}

${ }^{1}$ The full range of the scale is $1-5$. 
Similar results were obtained using different manipu lations of the independent variables (i.e. visual rathersemantic implicit priming) and different operationalization of the dependent variable (use of RT) (for review see Jarymowicz [38]). In all studies reviewed by her, there were significant differences between the positive and negative conditions for men but not for women.

Study 2 provides further evidence for the validity of Levi-Mayers hypothesis. It adds to the findings of study 1 by using completely different research paradigm (explicit in Study 1, versus implicit-in Study 2), with participants of different age (adults vs. adolescents), and nationality (Israeli vs. Polish) groups.

\section{Study 3}

One implication of women using CS less than men is that a woman's reaction to, and interpretation of, situations is less affected by her personality traits. This is because personality traits can be viewed as knowledge structures (schema) which predispose individuals to use them in interpreting new information. As with other types of pre-existing schema (e.g., expectations, attitudes, and stereotypes [39-42], personality traits can be viewed as cognitive structures [29,43-45]. For example, when comparing attitudes and traits, Sherman and Fazio [44] reviewed research regarding how one's character traits affect perception of and expectations about others and how these perceptions guide behavior in a trait-consistent manner. It can be argued, therefore, that the extent to which people are affected by their personality traits represents different degrees of use of cognitive structuring. To demonstrate this claim we chose to examine the relationship between trait and state anxiety. The choice of anxiety is based on the fact that state and trait anxiety are used more often than any other state-trait characteristic. Thus, we suggest that the relationship between trait and state anxiety represent CS because trait anxiety creates a negative bias in the processing of social information, especially in highly self-relevant situations where the self feels threatened. Similarly, it can be suggested that cognitive structuring is related to the effect of trait anxiety on a person's emotional distress in a fear-arousing situation.

Study 3 examined the effect of gender on relationships between state and trait anxiety, psychological distress and well-being among the first-degree relatives of patients in a cardiac intensive care unit. On the assumption that men use CS more than women, it was hypothesized that trait anxiety in men is a better predictor of state anxiety, psychological distress and well-being than in women.

\subsection{Method}

\subsubsection{Participants}

The sample comprised 44 male and 46 female first-degree relatives (spouse, sibling, child) of patients in a cardiac intensive care unit in Israel, who agreed to volunteer for the study (The response rate of the participants was 70\%). Participants' mean age was 43.04 years $(\mathrm{SD}=13.57)$ and mean years of schooling was $14.72(\mathrm{SD}=3.50)$. The patients' state of health, assessed by a physician in the Unit and ranked on a scale ranging from 1 "very mild" to 6 "very severe", averaged $3.59(\mathrm{SD}=1.35)$. There were no significant relationships between participants' gender and their characteristics (age, schooling, and category of kinship with the patient).

\subsubsection{Instruments}

State and trait anxiety: The Hebrew version [46] of the State-Trait Anxiety Inventory (STAI) [47] consists of 40 items: 20 measure trait anxiety and 20 state anxiety. The instructions preceding the trait measure direct participants to describe their feelings in general, while those of the state measure direct participants to describe their present feelings. In Study 3, the reliability scores for the state and trait anxiety scales were $\alpha=0.93$ and $\alpha=0.88$, respectively.

Psychological distress and well-being. Were measured by the Mental Health Inventory [48], comprising 38 items: 14 measure psychological well-being and 24 measure psychological distress. Questions refer to the participant's life during the past week. Responses to the items are given on a six-point scale from 1 "complete approval" to 6 "complete disapproval" of the item. The reliability scores for psychological distress and well- being were $\alpha$ $=0.91$ and $\alpha=0.90$, respectively.

\subsubsection{Procedure}

The study was conducted in a large university hospital in Israel. The study was approved by the Helsinki committee of the hospital. Participants were told that the study examined factors relating to the coping of individuals with the hospitalization of their first degree relatives in a cardiac intensive care unit. Participants were interviewed individually on the second or third day of their relative's admission to the Unit. Participants were assured that the data would serve research purposes only and that their participation or completion of the study would not affect the patient's treatment. Upon completion, participants were debriefed.

\subsection{Results and Discussion}

To test the study hypothesis that the correlations coefficients between trait anxiety and the participants' reports of their state are higher for men than for women, we calculated the correlation coefficients for each gender. Table 2 presents the correlation matrix of the study variables separately for each gender. The correlation between trait anxiety and the measures of state anxiety, distress, and well-being was significantly higher for men than women $(\mathrm{U}=2.08, \mathrm{p}<0.05 ; \mathrm{U}=2.57, \mathrm{p}=0.01$; and $\mathrm{U}=$ $1.82, \mathrm{p}<0.07$, respectively). Thus, this study validates the 
Table 2. Correlation matrix of variables in study 3 as a function of gender

\begin{tabular}{|c|c|c|c|c|c|c|c|c|}
\hline & \multicolumn{4}{|c|}{ Men } & \multicolumn{4}{|c|}{ Women } \\
\hline & 1 & 2 & 3 & 4 & 1 & 2 & 3 & 4 \\
\hline \multicolumn{9}{|l|}{ 1. State Anxiety } \\
\hline 2. Trait Anxiety & $0.61 * *$ & & & & 0.25 & & & \\
\hline 3. Psychological Distress & $0.60^{* *}$ & $0.63 * *$ & & & $0.55^{* *}$ & $0.36^{*}$ & & \\
\hline 4. Well Being & $-0.37 *$ & $-0.74 * *$ & $-0.83 * *$ & & $-0.33^{*}$ & $-0.31 *$ & $-0.72 * *$ & \\
\hline$M^{1}$ & 2.34 & 1.73 & 2.30 & 4.43 & 2.64 & 1.76 & 2.57 & 4.07 \\
\hline$S D$ & 0.66 & 0.44 & 0.75 & 0.87 & 0.67 & 0.40 & 0.81 & 0.92 \\
\hline
\end{tabular}

$*=\mathrm{p}<0.05 * *=\mathrm{p}<0.01 ; 1)$ The full range of both STAI scales is $1-4$ and that of the other scales is $1-6$

hypothesis that men use schematic thinking more than women do.

Few studies demonstrated similar effects. For example, Bar-Tal Gardosh, and Barnoy [49] demonstrated that the traits of negative affectivity and perception of control, measured before a coronary artery bypass graft, predicted significantly better symptom reporting after surgery for men than for women. Also, Eli, Bar-Tal, Fuss and Korff [50] found that pain tolerance of men is more affected by their trait anxiety than that of women (for similar results, see also, Edwards, Auguston and Fillings [51]) Similarly, Shepperd and Kashani [52] found that the components of hardiness (commitment and control) moderated the effect of stress on both physical and psychological symptoms in men. In women, hardiness components did not interact with stress in the prediction of health outcomes. However, Although the STAI is frequently used, little research has been done on the effect of gender on the state-trait relationship. Novy, Nelson, Goodwin and Rowzee [53] are among the very few whose results are related to the question. They found that the correlation among Caucasian in the US men was higher $(r=0.85)$ than among women $(r$ $=0.65)$. Although the authors did not report whether the difference was significant, it nevertheless is consistent with our results.

\section{General Discussion}

The focus of this article has been gender differences in the use of cognitive structuring. The three studies, deploying very different methods, showed that women tend to use less CS than men do. The studies not only functioned as theoretical replications of each other but were also supported by studies with more or less similar methodologies. The data and findings of the three studies clearly support the idea that men tend to use more CS (and therefore use more cognitive biases) than women do.

Whether there is a difference between genders in their accuracies or biases has been much researched but the results are equivocal. Some studies report greater accuracy and less bias in men than in women $[54,55]$. Other stud- ies show men less accurate than women [56,57]. Yet other studies show no gender difference in accuracy or bias $[58,59]$. The common denominator of these diverse studies is the use of outcomes to assess gender differences in accuracy and bias. That is, the judgment of the participant was compared to a given criteria (supposedly the truth) and the greater the discrepancy between the judgment and the criteria, the less accurate and more biased the judgment was judged to be. It is possible that the diversity of answers to the question of gender differences stem from this common feature. Accuracy of judgment may be related to different skills or motivations rather than to distortions of reality or biases [60-62].

Departing from this prescriptional approach, the present study takes a descriptive approach to the question. It examines whether there are gender differences in the cognitive processes men and women tend to use. More specifically, to what extent do men and women differ in their use of piecemeal vs. CS. Its results indicate that women tend to react more to the objective characteristics of a stimulus, while men react more to pertinent preexisting schema, which influence their perception.

Before concluding, it is necessary to consider the possibility that the gender differences reported in this paper are the results of specific contents involved in the studies (e.g., self-esteem), motivation and attention toward specific contents (interpersonal interaction). However, the diversity of the contents and experimental paradigms in this paper should be a reasonable answer to such threats. The contents in Study 1 and Study 3 were not related to self-esteem. Thus, in spite of the fact that participants' self esteem was part of Study 2, it is not reasonable to attribute the results of all three studies to the difference in self esteem between men and women. Similarly it is not reasonable to attribute the results mainly to difference between genders in the salience of health related issues (that are in the base of Study 3), because the other two studies do not utilize these contents. Likewise, it is not reasonable to attribute the results to the specific age or level of education of the participants because of the diversity of these characteristic in the three studies. 


\section{REFERENCES}

[1] S. Nemecek, "The Furor over Feminist Science," Scientific American, Vol. 276, No. 62, January 1997, pp. 99-100.

[2] J. Meyers-Levy, "Gender Differences in Information Processing: A Selectivity Interpretation," In: P. Cafferata and A. Tybout, Eds., Cognitive and Affective Responses to Advertising, Lexington Press, Lexington, MA, 1989, pp. 219-260.

[3] B. A. Martin, "The influence of gender on mood effects in advertising," Psychology and Marketing, Vol. 20, No. 3, 2003, pp. 249-273.

[4] J. Hayes, C. W. Allinson and S. J. Armstrong, "Intuition, Women Managers and Gendered Stereotypes," Personnel Review, Vol. 33, No. 4, 2004, pp. 403-417.

[5] S. L. Neuberg and J. T. Newsom, "Personal need for Structure: Individual Differences in the Desire for Simple Structure," Journal of Personality and Social Psychology, Vol. 65, No. 1, 1993, pp. 113-131.

[6] A. W. Kruglanski and E. P. Thompson, "Persuasion by a Single Route: A View from the Unimodel," Psychological Inquiry, Vol. 10, No. 2, 1999, pp. 83-109.

[7] M. B. Brewer, "A Dual Process Model of Impression Formation," In: T. K. Srull and R. S. Wyer, Eds., Advances in Social Cognition, Lawrence Erlbaum, New Jersey, 1988, pp. 1-36.

[8] R. M. Shiffrin and W. Schneider, "Controlled and Automatic Human Information Processing: II. Perceptual Learning, Automatic Attending, and a General Theory," Psychological Review, Vol. 84, No. 1, 1977, pp. 127-190.

[9] S. T. Fiske and P. W. Linville, "What does the Schema Concept Buy us?" Personality and Social Psychology Bulletin, Vol. 6, No. 4, 1980, pp. 543-557.

[10] J. R. Anderson, "The Adaptive Nature of Human Categorization," Psychological Review, Vol. 98, No. 3, 1991, pp. 409-429.

[11] C. N. Macrae and G. V. Bodenhausen, "Social Cognition: Thinking Categorically about Others," Annual Review, Vol. 51, No. 1, 2000, pp. 93-120.

[12] S. T. Fiske and S. E. Taylor, "Social Cognition," McGraw-Hill, Inc., New York, 1991.

[13] A. W. Kruglanski and D. M. Webster, "Motivated Closing of the Mind: 'Seizing' and 'freezing'," Psychological Review, Vol. 103, No. 2, 1996, pp. 263-283.

[14] A. W. Kruglanski and I. Ajzen, "Bias and Error in Human Judgment," European Journal of Social Psychology, Vol. 13, No. 1, 1983, pp. 1-44.

[15] J. Beattie and J. Baron, "Confirmation and Matching Biases in Hypothesis Testing," The Quarterly Journal of Experimental Psychology, Vol. 40, No. 2, 1988, pp. 269297.

[16] S. R. Evett, P. G. Devine, E. R. Hirt and J. Price, "The role of the Hypothesis and the Evidence tn the Trait Hypothesis Testing Process," Journal of Experimental Social Psychology, Vol. 30, No. 5, 1994, pp. 456-481.

[17] J. Baron, J. Beattie and J. C. Hershey, "Heuristics and Biases in Diagnostic Reasoning: II. Congruence, Infor- mation, and Certainty," Organizational Behavior and Human Decision Processes, Vol. 42, No. 1, 1988, pp. 88110.

[18] R. B. Marom and B. Fischhoff, "Diagnosticity and Pseudodiagnosticity," Journal of Personality and Social Psychology, Vol. 45, No. 6, 1983, pp. 1185-1195.

[19] J. Klayman and Y. Ha, "Hypothesis Testing in Rule Discovery: Strategy, Structure, and Content," Journal of Experimental Psychology: Learning Memory, and Cognition, Vol. 15, No. 4, 1989, pp. 596-604.

[20] M. Snyder and W. B. Swann, "Hypothesis-Testing Processes in Social Interaction," Journal of Personality and Social Psychology, Vol. 36, No. 11, 1978, pp. 1202-1212.

[21] M. Bassok and Y. Trope, "People's Strategies for Testing Hypothesis about Another'S Personality: Confirmatory of Diagnostic?" Social Cognition, Vol. 2, No. 12, 1984, pp. 199-216.

[22] P. G. Devine, E. R. Hirt, and E. M. Gehrke, "Diagnostic and Confirmation Strategies in Trait Hypothesis Testing," Journal of Personality and Social Psychology, Vol. 58, No. 6, 1990, pp. 952-963.

[23] R. B. Skov and S. J. Sherman, "Information-Gathering Processes: Diagnosticity, Hypothesis-Confirmatory Strategies, and Perceived Hypothesis Confirmation," Journal of Experimental Social Psychology, Vol. 22, No. 1, 1986, pp. 93-121.

[24] Y. Trope and M. Bassok, "Information-Gathering Strategies in Hypothesis-Testing," Journal of Experimental Social Psychology, Vol. 19, No. 6, 1983, pp. 560-576.

[25] A. W. Kruglanski and O. Mayseless, "Contextual Effects in Hypothesis Testing: The Role of Competing Alternatives and Epistemic Motivations," Social Cognition, Vol. 6, No. 1, 1988, pp. 1-21.

[26] D. M. Marsh and T. J. Hanlon, "Seeing What We Want to See: Confirmation Bias in Animal Behavior Research," Ethology, Vol. 113, No. 11, 2007, pp. 1089-1098.

[27] J. Chung and G. Monroe, "Gender Differences in Information Processing: An Empirical Test of the Hypothesis-Confirming Strategy an Audit Context," Accounting and Finance, Vol. 38, No. 2, 1998, pp. 265-79.

[28] T. B. Rogers, N. A Kuiper and W. S. Kirker, "SelfReference and the Encoding of Personal Information," Journal of Personality and Social Psychology, Vol. 35, 1977, pp. 677-688.

[29] H. Markus, "Self-Schemata and Processing Information about the Self," Journal of Personality and Social Psychology, Vol. 35, No. 1, 1977, pp. 63-78.

[30] A. G. Greenwald and A. R. Pratkanis, "The Self," In: R.S. Wyer Jr. and T. K. Srull, Eds., Handbook of Social Cognition, Lawrence Erlbaum, Hillsdale, 1984, pp. 129-177.

[31] M. H. Kernis (Ed.), "Self-Esteem Issues and Answers: A Sourcebook of Current Perspectives," Psychology Press, New York, 2006.

[32] S. T. Murphy and R. B. Zajonc, "Affect, Cognition and Awareness: Affective Priming with Optimal and Sub optimal Stimulus Exposures," Journal of Personality and Social Psychology, Vol. 64, No. 5, 1993, pp. 723-739.

[33] W. Blaszczak, "W Poszukiwaniu Specyfiki Utajonego 
Ja," Studia Psychologiczne, Vol. 39, No. 2, 2001, pp. 147-160.

[34] W. Blaszczak, "O efektach odnoszenia do Ja afektu wzbudzanego poza świadomością, In: R. K. Ohme, Ed., Nieuświa-domiony afekt, Gdańskie Wydawnictwo Psychologiczne, Gdańsk, 2007, pp. 157-163.

[35] M. R. Cadinu and M. Rothbart, "Self-Anchoring and Differentiation Processes in the Minimal Group Setting," Journal of Personality and Social Psychology, Vol. 70, No. 4, 1996, pp. 661-677.

[36] S. Otten and Y. Bar-Tal, "Self-Anchoring in The Minimal Group Paradigm: The Impact of Need and Ability to Achieve Cognitive Structure," Group Processes and Intergroup Relations, Vol. 5, No. 4, 2002, pp. 267-284.

[37] M. Lewicka, "Lista określeń do opisu właściwości człowieka," Przeglad Psychologiczny, Vol. 26, No. 6, 1983, pp. 703-713.

[38] M. Jarymowicz, "O roznicach plciowych w prze- twarzaniu informacji w warunkach wzbudzania afektu," Czasopismo Psychologiczne, Vol. 9, No. 3, 2003, pp. 231-242.

[39] J. Friedrich, "Primary Error Detection and Minimization (PEDMIN) Strategies in Social Cognition: A Reinterpretation of Confirmation Bias Phenomena," Psychological Review, 1993, pp. 298-319.

[40] J. L. Hilton and W. von Hippel, "Stereotypes," Annual Review of Psychology, Vol. 47, No. 1, 1996, pp. 237-271.

[41] S. L. Neuberg, "Expectancy-Confirmation Processes in Stereotype-Tinged Social Encounters: The Moderating Role of Social Goals," In: M. P. Zanna and J. M. Olson, Eds., The Psychology of Prejudice: The Ontario Symposium, Lawrence Erlbaum, Hilsdale, 1994, pp. 103-130.

[42] Stangor and D. McMillan, "Memory for ExpectancyCongruent and Expectancy-Incongruent Information: A Review of the Social and Social Developmental Literatures," Psychological Bulletin, Vol. 111, No. 1, 1992, pp. 42-61.

[43] Sedikides and J. J. Skowronski, "The Law of Cognitive Structure Activation," Psychological Inquiry, Vol. 2, No. 2, 1991, pp. 169-184.

[44] S. J. Sherman, and R. H. Fazio, "Parallels between Attitudes and Traits as Predictors of Behavior," Journal of Personality, Vol. 51, No. 3, 1983, pp. 308-345.

[45] S. S. Smith, and J. F. Kihlstrom, "When is a Schema not a Schema? The "big five' Traits as Cognitive Structures," Social Cognition, Vol. 5, No. 1, 1987, pp. 26-57.

[46] Y. Y. Teichman and C. Melinak, "State-Trait Anxiety Questionnaire: Hebrew-Language Guide for Testers," 2nd Edition, Psychology Department, Tel Aviv University, Tel-Aviv, Israel, [In Hebrew], 1979.

[47] C. C. Spielberger, "Preliminary Manual for the State-Trait Personality Inventory," Human Resources Institute, University of South Florida, Tampa, 1980.

[48] C. T. Veit and J. E. Ware, "The Structure of Psychological Distress and Well-Being in General Populations," Journal of Consulting and Clinical Psychology, Vol. 51, No. 5, October 1983, pp. 730-42.
[49] Y. Bar-Tal, H. Gardosh and S. Barnoy, "The Differential Effect of Perceived Control and Negative Affectivity as a Function of Gender after Coronary Artery Bypass Graft Surgery," Sex Roles, Vol. 55, No. 11, 2006, pp. 853-859.

[50] I. Eli, Y. Bar-Tal, Z. Fuss and E. Korff, "Effect of Biological Sex Differences on the Perception of Acute Pain Stimulation in The Dental Setting," Pain and Research Management, Vol. 1, No. 4, 1996, pp. 201-206.

[51] R. Edwards, E. M. Auguston and R. Fillingim, "Sex Specific Effects of Pain Related Anxiety on Adjustment to Chronic Pain," Clinical Journal of Pain, Vol. 16, No. 1, 2000, pp. 46-53.

[52] J. A. Shepperd and J. H. Kashani, "The Relationship of Hardiness, Gender, and Stress to Health Outcomes in Adolescents," Journal of Personality, Vol. 59, No. 4, 1991, pp. 747-768.

[53] D. M. Novy, D. V. Nelson, J. Goodwin and R. D. Rowzee, "Psychometric Comparability of the State-Trait Anxiety Inventory for Different Ethnic Subpopulations," Psychological Assessment, Vol. 5, No. 3, 1993, pp. 343-349.

[54] S. Mann, "Who Killed my Relative? Police Officers' Ability to Detect Real-Life High-Stake Lies," Psychology, Crime and Law, Vol. 7, No. 2, 2001, pp. 119-132.

[55] Y. Bar-Tal, S. Barnoy and B. Zisser, "Whose Informational Needs are Considered? A Comparison between Cancer Patients and Their Spouses' Perception of their Own and their Partners' Knowledge and Informational Needs," Social Science and Medicine, Vol. 60, No. 7, 2005, pp. 14591460 .

[56] J. A. Hall, "Nonverbal Sex Differences: Communication Accuracy and Expressive Style," John Hopkins University Press, Baltimore, 1984.

[57] S. Beyer, "Gender Differences in the Accuracy of Grade Expectancies and Evaluations," Sex Roles, Vol. 41, No. 3, 1999, pp. 279-296.

[58] H. Holling and F. Preckel, "Self-Estimates of IntelligenceMethodological Approaches and Gender Differences," Personality and Individual Differences, Vol. 38, No. 3, 2005, pp. 503-517.

[59] D. A. Kenny and L. K. Acitelli, "Accuracy and Bias in the Perception of the Partner in a Close Relationship," Journal of Personality and Social Psychology, Vol. 80, No. 3, 2001, pp. 439-448.

[60] K. J. Klein, and S. D. Hodges, "Gender Differences, Motivation, and Empathic Accuracy: When it Pays to Understand," Personality and Social Psychology Bulletin, Vol. 27, No. 6, 2001, pp. 720-730.

[61] C. Lewin, G. Wolgers and A. Herlitz, "Sex Differences Favoring Women in Verbal But Not in Visuospatial Episodic Memory," Neuropsychology, Vol. 15, No. 2, 2001, pp. 165-173.

[62] P. L. Ackerman, K. R. Bowen, M. E. Beier and R. Kanfer, "Determinants of Individual Differences and Gender Differences in Knowledge," Journal of Educational Psychology, Vol. 93, No. 4, 2001, pp. 797-825. 